\begin{tabular}{|l|l|}
\hline & $\begin{array}{l}\text { HHS PUbIC ACCOSS } \\
\text { Author manuscript } \\
\text { JAMA. Author manuscript; available in PMC 2016 June } 07 .\end{array}$ \\
\hline
\end{tabular}

Published in final edited form as:

JAMA. 2015 January 6; 313(1): 91. doi:10.1001/jama.2014.15898.

\title{
Management of Patients With Sickle Cell Disease
}

\author{
Elizabeth S. Klings, MD1, Gregory J. Kato, MD², and Mark T. Gladwin, MD ${ }^{3}$ \\ ${ }^{1}$ Pulmonary Center, Boston University School of Medicine, Boston, Massachusetts \\ ${ }^{2}$ Division of Hematology and Oncology, University of Pittsburgh, Pittsburgh, Pennsylvania \\ ${ }^{3}$ Division of Pulmonary, Allergy and Critical Care Medicine, University of Pittsburgh, Pittsburgh, \\ Pennsylvania
}

\section{To the Editor}

As members of the guideline committee sponsored by the American Thoracic Society on the diagnosis and treatment of pulmonary hypertension in patients with $\mathrm{SCD}$, ${ }^{1}$ we would like to emphasize several important differences between our guidelines and the pulmonary hypertension recommendations made by Dr Yawn and colleagues. ${ }^{2}$ We concur that an echocardiogram is an essential part of the evaluation of patients with SCD and unexplained dyspnea and that right heart catheterization is required for diagnosis of pulmonary hypertension.

However, the prevalence of pulmonary hypertension defined by right heart catheterization in SCD (10\%) is comparable with other disorders such as systemic sclerosis, in which the accepted standard of care is to screen for pulmonary hypertension by echocardiography. ${ }^{3}$ Patients with an elevated tricuspid regurgitant jet velocity are often asymptomatic and pulmonary hypertension may be advanced by the time that dyspnea is recognized by clinicians, ${ }^{4}$ supporting the use of echocardiography screening for both mortality risk assessment and early diagnosis of pulmonary hypertension in patients with SCD. ${ }^{5}$

It remains unproven whether screening of asymptomatic patients changes outcomes, but it is well documented that echocardiography identifies a group of high-risk patients with SCD who may have treatable contributory factors such as chronic thromboembolism, sleepdisordered breathing, or exercise and nocturnal hypoxemia. ${ }^{1}$ Furthermore, stratification of high-risk patients with echocardiography, elevated levels of plasma $\mathrm{N}$-terminal brain natriuretic peptide, or pulmonary hypertension defined by right heart catheterization could identify a group of patients whose SCD treatment could be intensified using proven effective therapies such as hydroxyurea or chronic transfusion.

It was the consensus of the American Thoracic Society expert committee that an intensive clinical evaluation of high tricuspid regurgitant jet velocity is indicated in patients with SCD aged 18 years or older due to the documented risk of high mortality. Screening echocardiography prior to age 18 years may be considered; however, there is no consensus for routine use of echocardiography in asymptomatic children and adolescents. Although the risk of pulmonary arterial hypertension is mentioned in the guideline document by Yawn et 
al,2 pulmonary venous hypertension is also prevalent in patients with SCD and associated with increased mortality, particularly in those with high transpulmonary pressure gradients.

There is a strong need for additional large-scale clinical trials of SCD on which treatment recommendations can be based.

\section{References}

1. Klings ES, Machado RF, Barst RJ, et al. American Thoracic Society Ad Hoc Committee on Pulmonary Hypertension of Sickle Cell Disease. An official American Thoracic Society clinical practice guideline: diagnosis, risk stratification, and management of pulmonary hypertension of sickle cell disease. Am J Respir Crit Care Med. 2014; 189(6):727-740. [PubMed: 24628312]

2. Yawn BP, Buchanan GR, Afenyi-Annan AN, et al. Management of sickle cell disease: summary of the 2014 evidence-based report by expert panel members. JAMA. 2014; 312(10):1033-1048. [PubMed: 25203083]

3. Hoeper MM, Bogaard HJ, Condliffe R, et al. Definitions and diagnosis of pulmonary hypertension. J Am Coll Cardiol. 2013; 62(25 (suppl)):D42-D50. [PubMed: 24355641]

4. Klings ES, Anton Bland D, Rosenman D, et al. Pulmonary arterial hypertension and left-sided heart disease in sickle cell disease: clinical characteristics and association with soluble adhesion molecule expression. Am J Hematol. 2008; 83(7):547-553. [PubMed: 18383329]

5. Mehari A, Gladwin MT, Tian X, Machado RF, Kato GJ. Mortality in adults with sickle cell disease and pulmonary hypertension. JAMA. 2012; 307(12):1254-1256. [PubMed: 22453563] 